\title{
Social inferences from group size
}

\author{
Jack Cao ${ }^{\mathrm{a}^{*}}$ and Mahzarin R. Banaji ${ }^{\mathrm{a}}$ \\ ${ }^{\text {a} D e p a r t m e n t ~ o f ~ P s y c h o l o g y, ~ H a r v a r d ~ U n i v e r s i t y, ~ C a m b r i d g e, ~ M A ~} 02138$
}

Keywords: group size; group perception; status; competence; Implicit Association Test

*Please address correspondence to:

Jack Cao

Department of Psychology, Harvard University

33 Kirkland Street, Room 1570

Cambridge, MA 02138 USA

(504) 281-0442

jackcao@fas.harvard.edu 


\begin{abstract}
What social inferences about groups are made solely on the basis of their relative size? Study 1 showed that smaller and larger groups are rated equally on warmth/goodness and that because socioeconomic elites (i.e., the 1\%) are few in number, smaller groups are rated higher on status/competence than larger groups. Using an implicit measure (the IAT), Studies 2 and 3 demonstrated that smaller and larger groups are equally associated with warmth/goodness, replicating the previous result. However, on the IAT, it is larger groups that are associated with high status/competence, not smaller groups. We rule out two possible explanations for this explicit-implicit dissociation. Compared to smaller groups, larger groups are not implicitly associated with greater amounts of any attribute, nor are larger groups implicitly associated with all positive attributes. Study 4 found that even when two groups are explicitly known to be the same in status/competence, the larger group is nonetheless associated with high status/competence. To explain this dissociation, we offer the possibility that implicit associations between larger groups and high status/competence are systematic, erroneous extensions of the association between larger groups and physical dominance. Together, these studies reveal a new dissociation between explicit and implicit cognition: although explicit cognition recognizes that larger groups are not always elite, implicit cognition falls prey to a bias that incorrectly translates the physical dominance of larger groups into elite status, thereby giving larger groups expanded power in the minds of perceivers.
\end{abstract}




\section{Introduction}

Imagine entering a room and noticing that there are two groups of people, those dressed in red and those dressed in blue, with the blues greatly outnumbering the reds. If these two groups are equivalent on all other dimensions except relative size, what psychological properties do we, as perceivers, attribute to these groups? And on the basis of group size alone, is there consistency between the attributes that are explicitly reported and those that are implicitly revealed?

Although group size is among the most common perceptual cues that distinguish groups within societies, surprisingly little is known about how this cue shapes social perception. With excellent returns, contemporary research on groups has largely focused on wide scale intergroup conflict (Hewstone et al., 2002) and on the dynamics of small group interactions (Levine \& Moreland, 1990; Worchel, Axsom, et al., 1978). But rarely has group size been isolated to understand whether and how it influences what perceivers infer about groups' psychological properties.

Yet early in the history of groups research, such efforts were at the forefront. Lewin (1947) theorized that a group's psychological attributes are more than simply the sum of group members' individual attributes. Allport (1954) discussed the implications of group perception for stereotyping and prejudice. Campbell (1958) imported ideas from Gestalt psychology to posit that group members' similarity and proximity to one another influence beliefs about the group's entitativity. Later empirical work not only confirmed Campbell's claim (Dasgupta, Banaji, \& Abelson, 2000; Lickel et al., 2000), but also demonstrated how entitativity influences social cognition (Hamilton, Sherman, \& Castelli, 2002).

To be sure, group size has not been fully ignored as a variable of interest. Evolutionary biologists and developmental psychologists have found that across phylogeny and ontogeny, group size corresponds closely to beliefs about physical dominance (Wilson \& Wrangham, 2003; Pietrasewski \& Shaw, 2015; Pun, Birch, \& Baron, 2016). The larger a group is, the greater the belief in the group's ability to impose costs on competing groups and for the group to prevail during conflict (Maynard Smith \& Parker, 1976; McComb et al., 1994). In the domain of group performance, majority groups have been shown to sway individuals to conform to an obviously 
wrong position (Asch, 1951). And members of larger groups have been found to cooperate less, exhibit greater amounts of misbehavior, and be less satisfied (Latane, 1981; Kerr, 1989; Markham et al., 1982; Pinto \& Crow, 1982).

But still the question remains of how group size affects which psychological properties perceivers attribute to different groups. With the exception of gender, all other major social groups - different races/ethnicities, religions, castes, and sexualities - vary greatly in size. Given the ubiquity of group size, especially as groups change markedly in size (Craig \& Richeson, 2014), it is important to understand this cue's influence on fundamental social inferences concerning warmth, goodness, status, and competence. The present research aims to fill this gap and is rooted theoretically in the Stereotype Content Model, which has identified two primary dimensions of group perception: warmth and competence (Fiske et al., 2002; Fiske, Cuddy, \& Glick, 2006). However, the current work expands the warmth dimension to include attributes such as nice, pleasant, and honest - leading to the label warmth/goodness. The competence dimension is expanded even more to include attributes related to socioeconomic status - such as rich, classy, and business class - leading to the label status/competence.

In the first study, participants were shown two groups that differ solely in size and were asked to rate each group on attributes related to warmth/goodness and status/competence. Thus, we collected ratings of two minimal groups, with relative size rather than group membership manipulated, as Tajfel \& Turner (1986) did before. In later studies, the Implicit Association Test (IAT; Greenwald, McGhee, \& Schwartz, 1998) was used to assess whether implicit associations are consistent with explicit ratings, something early researchers were unable to pursue.

In conducting this research, it was not immediately clear how group size would, if at all, affect perceptions of warmth/goodness, which are typically based on a group's motives and its past and present behaviors (Reeder et al., 2002). On the one hand, a larger group's greater numbers may signal less familiarity and closeness and therefore less warmth/goodness, leading the smaller group to be viewed as warmer/better. But on the other hand, a smaller group may be viewed as more isolated while a larger group may be seen as offering greater opportunities for social interaction, leading the larger group to be viewed as warmer/better. Finally both 
groups may be viewed as equally warm/good. At present, how group size affects perception along this dimension is unknown, and the current studies can be the first to suggest an answer.

Status/competence is the second dimension of interest. Our measures primarily focused on status-related attributes (e.g., rich, classy, business class) because of the importance of status to social hierarchies and to perceptions of competence (Magee \& Galinsky, 2008; Fiske et al., 2002). In fact, Fiske et al. (2002) found a near perfect correlation between ratings of status and ratings of competence, which might reflect a belief that high status cannot emerge without high competence. There is also a strongly held consensus that socioeconomic elites are few in number, even though the degree of economic inequality is underestimated (Norton \& Ariely, 2011). Furthermore, media coverage of events like the Occupy movement and the top $1 \%$ of earners (e.g., Moynihan, 2015) may have increased the salience of how small the socioeconomic elite are compared to the larger group of people of more modest means. Together, these reasons lead to the hypothesis that high status/competence attributes will be associated with smaller rather than larger groups.

The primary focus here is on whether smaller groups will be linked with high status/competence on both explicit and implicit measures. On explicit ratings, smaller groups may be rated as high in status/competence. But on the IAT, larger groups may be incorrectly associated with high status/competence because of an overgeneralization from the association between larger groups and physical dominance. In fact, explicit and implicit attitudes and beliefs towards the same target have been shown to dissociate (Rydell et al., 2007; Nosek et al., 2007) and influence group-based thinking (Macrae \& Bodenhausen, 2000). Frequently, these dissociations appear in domains where the demand to appear egalitarian is strong (Nosek, 2005). But the targets in the forthcoming studies are unnamed, abstract groups that differ solely in size. As such, pressure to appear egalitarian need not apply.

Therefore, the extent to which we observe an explicit-implicit dissociation on the dimension of status/competence will be instructive for theories of group perception. For if implicit associations indicate that high status/competence accrues to larger groups while explicit ratings indicate otherwise, then we must attempt to understand this dissociation in ways other than the demand to respond in a socially acceptable manner. New theorizing would 
be necessary to explain why conscious inferences from group size align with the social reality that smaller groups tend to hold high socioeconomic status, but why less conscious inferences reflect the view that such high status is held by larger groups.

\section{Study 1a}

A preliminary study was conducted to test explicit ratings of warmth/goodness and status/competence. Two hundred and fifty participants were recruited from Amazon Mechanical Turk $\left(M_{\mathrm{age}}=36.30\right.$ years, $S D=12.80 ; 130$ males, 120 females $) .{ }^{1}$ All participants completed twenty trials in which they were shown an image of a smaller group of 6 stick figures and a larger group of 12 stick figures. Below the image were two opposing attribute pairs that had to be matched with the two groups in a forced choice task. The first three trials consisted of practice pairs (e.g., light vs. heavy) to acclimate participants to the task. ${ }^{2}$ The remaining trials pertained to physical dominance (i.e., strong vs. shaky; powerful vs. helpless), warmth/goodness (e.g., warm vs. cold; pleasant vs. unpleasant), or status/competence (e.g., smart vs. stupid; rich vs. poor). ${ }^{3}$ Thus, all participants rated the smaller and larger groups on all attribute pairs.

If the larger group is matched with strong and powerful-consistent with intuition and past work demonstrating the physical power of larger groups over smaller groups - then we are provided with a reassuring baseline verification that allows us to interpret more confidently the results from the dimensions of warmth/goodness and status/competence. All stimuli are in the appendix. Trial order for non-practice attribute pairs and the location of the groups within the image were randomized. For all studies in this paper, we report all measures, manipulations, and exclusions.

\footnotetext{
${ }^{1}$ Sample size for all studies was determined before the start of data collection.

${ }^{2}$ Please see appendix for results of the practice trials.

${ }^{3}$ Four other pairs were also tested (envied vs. disgusting; admired vs. pitied; envied vs. admired; pitied vs. disgusting). These four pairs consist of emotions that arise from specific high-low combinations of warmth and competence. The focus of this paper is not on these second-order emotions. Thus, the results of these four pairs are in the appendix. It is unlikely that these four pairs biased the results in Figure 1 because attribute pairs were tested in a random order.
} 
Figure 1. Proportion of participants in Study 1a who matched each attribute with the larger group. The horizontal line indicates chance level responding. Error bars are $95 \% \mathrm{Cls}$.
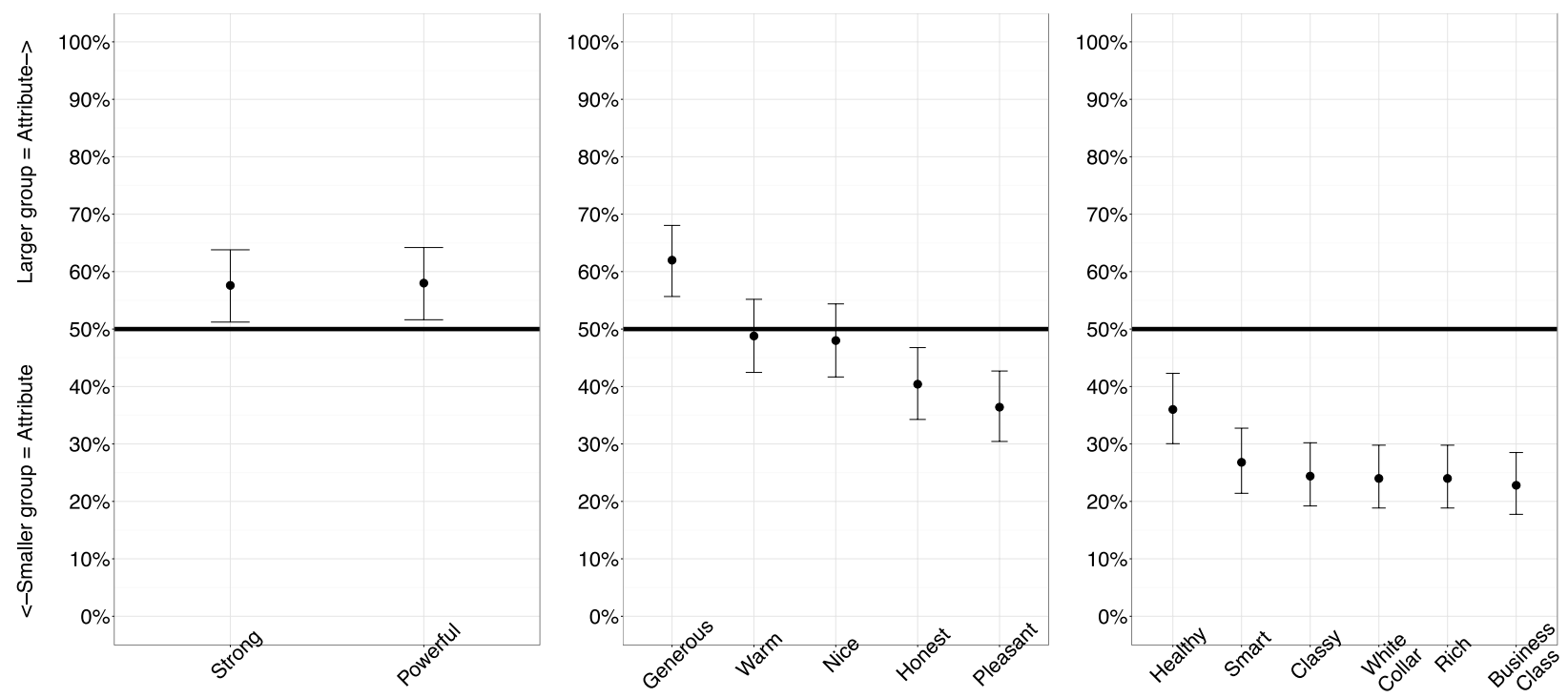

Results and Discussion. Figure 1 organizes the attributes according to dimension and displays the proportion of participants who matched each attribute with the larger group. Given the forced choice nature of the task, values greater than $50 \%$ indicate an explicit rating that the larger group is associated with the attribute, whereas values less than $50 \%$ indicate an explicit rating that the smaller group is associated with the attribute. Three results emerge.

First, as expected, the larger rather than smaller group was rated as strong and powerful $(58 \%$, binomial $p s<.02)$. This effect was smaller than would be expected based on the generally accepted belief that larger groups will trounce smaller groups in physical conflict. The observed result may therefore reflect attempts to imagine when smaller groups may, through their high status/competence, achieve greater strength and power (e.g., minority rule over majorities), leading to a less extreme rating of larger groups as stronger and more powerful. We return to this point in Study 2 where an implicit measure is used.

Second, the smaller and larger groups were rated as equally warm/good, as no systematic pattern emerged with the attributes of generous $(62 \%, p<.001)$, warm $(49 \%, p=$ $.75)$, nice $(48 \%, p=.57)$, honest $(40 \%, p=.003)$, or pleasant $(36 \%, p<.0001)$. The lack of a systematic pattern on the dimension of warmth/goodness is striking in comparison to the third 
result, which makes clear that status/competence attributes do systematically differentiate between groups of different sizes. As predicted, the high status/competence attributes of healthy, smart, classy, white collar, rich, and business class were rarely matched with the larger group $(<37 \%$, ps < .0001). Instead, it was the smaller group that was rated as high in status/competence. Notably, the biggest effect was produced by the attribute that has an extremely obvious relationship with group size: business class is, of course, smaller than economy class, and participants clearly recognized this $(23 \%, p<.0001)$.

These initial results show that on the dimension of warmth/goodness, smaller and larger groups are rated equally. But smaller, not larger, groups are rated as high in status/competence. We assume that the latter result stems from common knowledge that wealth and status tend to be concentrated in smaller groups of people. In later studies that use the IAT, we test if this common knowledge also influences implicit associations between different sized groups and status/competence, or if implicit associations deviate substantially from explicit ratings.

\section{Study 1b}

Study $1 \mathrm{~b}$ sought to establish that smaller groups are rated as high in status/competence because of the common knowledge that wealth and status tend to be concentrated in smaller groups. Three hundred participants were recruited from Amazon Mechanical Turk $\left(M_{\text {age }}=31.74\right.$ years, $S D=9.64 ; 179$ males, 119 females, 2 unspecified) and were randomly assigned to one of three conditions in a between-subjects design: 1) rich vs. poor, 2) smart vs. stupid, or 3) professional class vs. working class. Participants answered 10 questions of the form, "Which group is $X$ ?" where $X$ was an attribute. Five questions tested the positive attribute (e.g., rich) and its synonyms (e.g., wealthy) and five questions tested the negative attribute (e.g., poor) and its synonyms (e.g., penniless). The two answer choices, which were counterbalanced, consisted of a smaller group of 6 stick figures or a larger group of 12 stick figures.

To obtain explanations for their answers, participants were invited to endorse a reason for their ratings. One reason was consistent with our assumption that common knowledge was brought to bear (e.g., In the real world, wealth is concentrated in smaller groups of people). A 
second reason was consistent with the opposite notion that more people in a group means it has more of a resource (e.g., More people in a group means the group has more collective wealth). Participants were able to endorse one, both, or neither reason.

Figure 2. Proportion of participants in Study $1 \mathrm{~b}$ who matched each attribute with the larger group. The horizontal line indicates chance level responding. Error bars are $95 \% \mathrm{Cls}$.
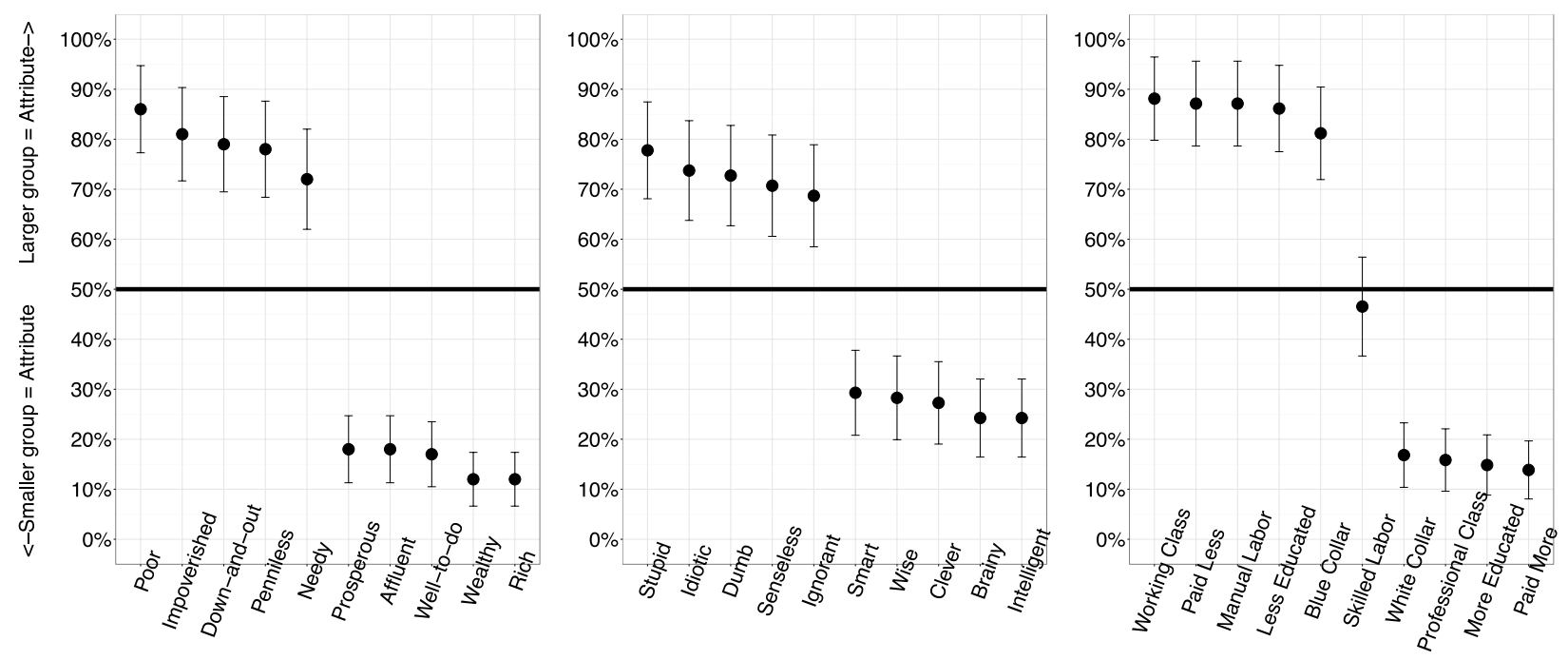

Results and Discussion. Replicating the results of Study 1a, Figure 2 shows that in Study 1b, smaller groups are rated as high in status/competence, while larger groups are rated as low in status/competence. This pattern held for all synonyms tested (binomial $p$ s $<.001$ ) with the exception of skilled labor $(p=.55){ }^{4}$

Participants' explanations for their ratings confirm that a common understanding that elites are few in number was brought to bear: $87 \%$ of participants in the rich condition endorsed the reason that wealth is concentrated in smaller groups; $59 \%$ of participants in the smart condition endorsed the reason that education is concentrated in smaller groups; and 83\% of participants in the professional class condition endorsed the reason that socioeconomic

\footnotetext{
${ }^{4}$ For each participant, a Cohen's kappa was calculated comparing his or her responses to a hypothetical set of responses in which the smaller group was always rated as high in status/competence and the larger group was always rated as low in status/competence. The average Cohen's kappa in the rich, smart, and professional class conditions were $0.64,0.46$, and 0.64 , respectively, all of which indicate moderate to substantial agreement.
} 
status is concentrated in smaller groups. As one participant commented, "It's the whole $1 \%$ thing - the higher you get in terms of pay and education, the smaller the group is."

Studies $1 \mathrm{a}$ and $1 \mathrm{~b}$ demonstrate that smaller and larger groups are rated as equally warm/good. But smaller groups are rated as higher in status/competence than larger groups because socioeconomic elites are indeed few in number. Study 2 was conducted to test the main question of interest: are implicit associations between groups of different sizes and warmth/goodness and status/competence consistent with explicit ratings? Both association and dissociation are possible, and we sought to establish which is the case and explain why.

\section{Study 2}

Participants. Participants were volunteer visitors to Project Implicit (implicit.harvard.edu). Of the 2318 participants who completed the procedure, 36 were excluded for going faster then 300 ms on $10 \%$ or more of trials, in accordance with the scoring algorithm established by Greenwald, Nosek, \& Banaji (2003) and well within expected rates. The final sample consisted of 2282 participants ( $M_{\text {age }}=32.40$ years, $S D=13.54 ; 1435$ females, 825 males, 22 unspecified).

Methods. In five independent rounds of data collection, participants took one IAT in which the concepts were 6 vs. 12 in number form to represent the smaller and larger groups. The attributes consisted of all the pairs shown in Figure 1 (e.g., White Collar vs. Blue Collar), with each participant randomly receiving only one attribute pair in a between-subjects design. ${ }^{5}$ Stimuli for the concepts were images of stick figure groups with either 6 or 12 individuals. Stimuli for the attributes were synonyms for the attributes or related words (e.g., CEO for White Collar and mailman for Blue Collar). All stimuli are available in the appendix. In one critical block of the IAT, participants sorted stimuli into two categories that matched a group size with an attribute (e.g., 6+White Collar, 12+White Collar). In the next critical block these

\footnotetext{
${ }^{5}$ There were two differences between the stimuli in Study 1a and the stimuli in Study 2. First, for the attribute pairs Healthy vs. Sick, Generous vs. Stingy, and Powerful vs. Helpless, we used 9 and 21 stick figures instead of 6 and 12. Second, in Study 2, the categories were Honest vs. Liar instead of Honest vs. Dishonest. It is extremely unlikely that these slight differences affected the results. The stimuli used to represent Liar were all synonyms of Dishonest (e.g., Deceitful, see appendix), and a larger group of 21 was associated with powerful, just as a larger group of 12 was associated with strong.
} 
categories were reversed (e.g., 12+White Collar, 6+White Collar). The order of the critical blocks was counterbalanced.

Figure 3. Mean IAT D scores by attribute in Study 2. Error bars are $95 \% \mathrm{Cls}$.
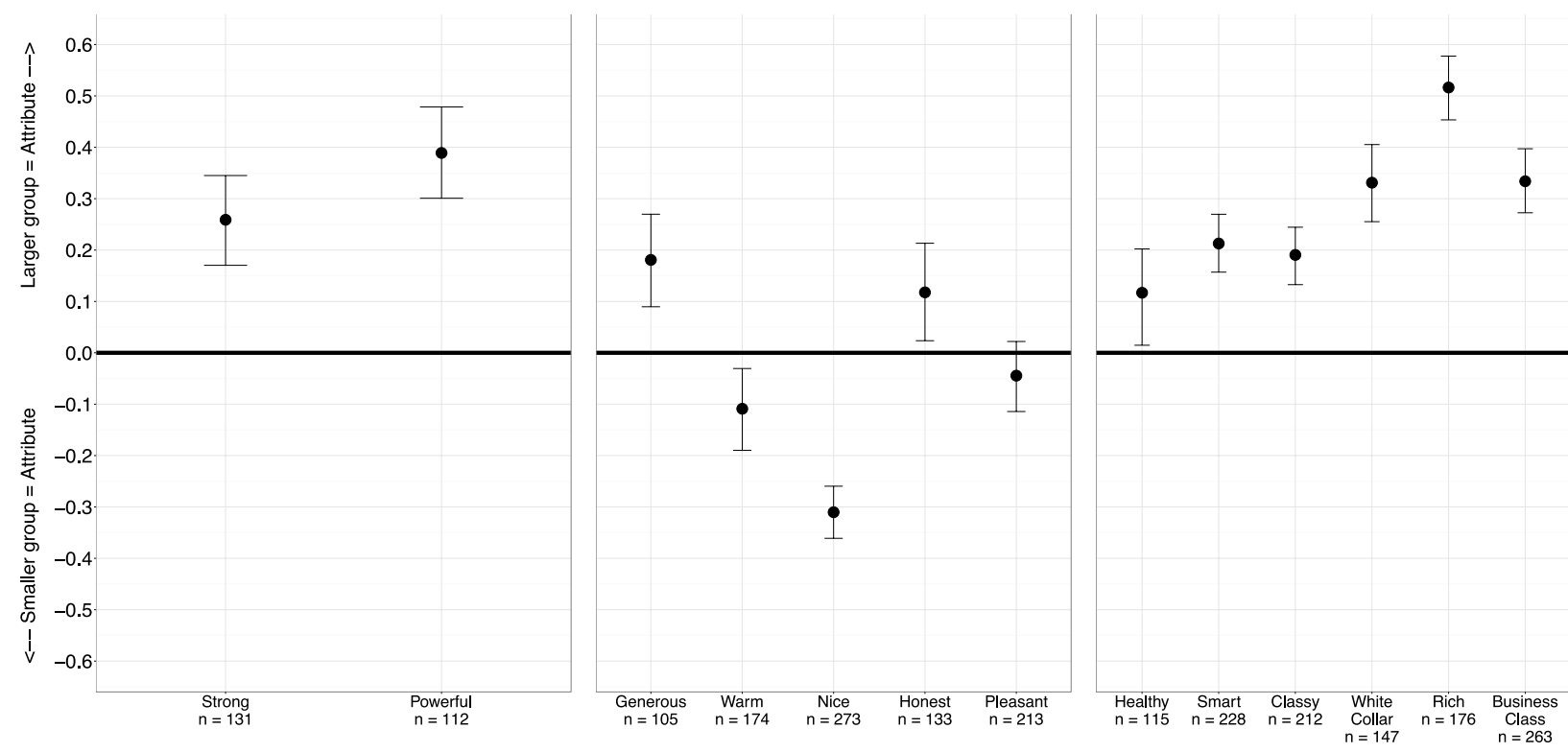

Results and Discussion. Figure 3 organizes the attributes according to dimension and in the same order as they appear in Figure 1. Positive values indicate an implicit association between the larger group and the attribute. Negative values indicate an implicit association between the smaller group and the attribute. Three results emerge.

First, larger relative to smaller groups are implicitly associated with strong $(M=0.26, S D$ $=0.50$, one-sample $t(130)=5.91, p<.0001$, Cohen's $d=0.52)$ and powerful $(M=0.39, S D=$ 0.49 , one-sample $t(111)=8.41, p<.0001$, Cohen's $d=0.79)$. The consistency between explicit ratings and implicit associations on these attributes provides face validity for using the IAT to test attributes related to warmth/goodness and status/competence. Furthermore, it is notable that only $58 \%$ of participants in Study 1 a explicitly rated the larger group to be strong and powerful, but over $72 \%$ of participants implicitly associated the larger group with these attributes. Whereas the high status/competence of smaller groups may have influenced explicit ratings of strength and power, leading to reduced effects in Study 1a, this was not the case on 
the implicit measure where larger groups are clearly stronger and more powerful than smaller groups.

In studies $1 \mathrm{a}$ and $1 \mathrm{~b}$, smaller groups were rated as high in status/competence. But here in Study 2, larger groups were associated with high status/competence, in direct contrast to the explicit ratings observed before. Larger groups were implicitly associated with healthy $(M=$ $0.12, S D=0.50$, one-sample $t(114)=2.52, p=.01$, Cohen's $d=0.23)$ and with classy, smart, white collar, business class, and rich (Ms > 0.19, one-sample ts $>6.15, p s<.0001$, Cohen's $d s>$ 0.42). These data highlight a stark dissociation in how the status/competence of different sized groups are perceived.

The specific attribute of business class clearly illustrates this dissociation. It is blatantly obvious that business class is smaller than economy class, and explicit ratings reflect this understanding. But on an implicit measure, it is the larger rather than smaller group that is associated with business class $(M=0.33, S D=0.50$, one-sample $t(262)=10.73, p<.0001$, Cohen's $d=0.66)$.

One explanation for this dissociation may be that larger groups are implicitly associated with more of any attribute. If this were the case, then larger groups would also be associated with more warmth/goodness. However, the third result rules out this possibility, as there is no systematic relationship between group size and warmth/goodness. Replicating the explicit ratings obtained in Study 1a, smaller and larger groups are equally associated with attributes from this dimension. Whereas smaller groups were associated with nice and warm (Ms $<-0.10$, one-sample $t s<-2.65, p s<.009$, Cohen's $d s>0.20)$, larger groups were associated with honest and generous (Ms $>0.11$, one-sample $t s>2.35, p s<.03$, Cohen's $d s>0.20$ ).

Another possible explanation is that on the IAT, larger groups are simply perceived as better than smaller groups. However, neither the smaller nor larger group was associated with pleasant $(M=-0.04, S D=0.50$, one-sample $t(212)=-1.31, p=.19)$. This null finding indicates that the implicit association between larger groups and high status/competence reflects meaningful semantic content rather than general positivity. In sum, these results show that larger groups are not perceived as having "more" of all attributes nor as they perceived to be 
merely better than smaller groups. Larger groups are robustly associated with high status/competence, contrary to what is expressed on self-report measures.

\section{Study 3}

The dissociation between explicit ratings and implicit associations on the status/competence dimension was found from two different participant pools: Amazon Mechanical Turk (Studies 1a and 1b) and Project Implicit (Study 2). These different samples leave open the possibility that the result does not represent a dissociation within one and the same mind. But if participants from the same sample report that smaller groups are high in status/competence but implicitly associate larger groups with high status/competence, then such a result would be far more striking. Study 3 is both a replication and a test of the explicitimplicit dissociation in a more robust within-subjects design. Here, we focus on the attribute pairs of rich vs. poor, professional class vs. working class, and business class vs. economy class. ${ }^{6}$ Data from Study $1 \mathrm{~b}$ show that participants are well aware that the rich and professional class are groups of smaller size. And as anyone who has traveled on a commercial airline can report, business class is obviously smaller than economy class. Thus, we should be least likely to observe an explicit-implicit dissociation with these three attribute pairs.

Participants. Participants were volunteer visitors to Project Implicit. Of the 720 participants who completed the IAT, 7 were excluded for going faster than 300 ms on $10 \%$ or more of trials, in accordance with the Greenwald, Nosek, \& Banaji (2003) and well within expected rates. An additional 44 participants were excluded for not completing all explicit measures. The final sample consisted of 669 participants $\left(M_{\mathrm{age}}=36.90\right.$ years, $S D=14.06 ; 419$ females, 237 males, 13 unspecified).

Methods. First, participants completed an IAT in which the concepts were Group of 6 People vs. Group of 12 People and the attributes were Rich vs. Poor, Business Class vs. Economy Class, or

\footnotetext{
${ }^{6}$ We also tested the attribute pairs of smart vs. stupid and educated vs. ignorant in a within-subjects design. However, explicit ratings of which group is smart and educated indicated that participants did not consistently interpret the meanings of these attributes. We present and discuss these data in the appendix.
} 
Professional Class vs. Working Class. One of these three attribute pairs was randomly assigned to each participant in a between-subjects design. Stimuli for the concepts were images of a group of 6 or 12 stick figures, as before. Stimuli for the attributes are available in the appendix. The order of the critical blocks was counterbalanced. As before, $D$ scores were calculated such that negative values indicate an implicit association between the smaller group and the positive attribute (i.e., rich, business class, professional class) and positive values indicate an implicit association between the larger group and the positive attribute.

After completing the IAT, participants answered ten explicit questions similar to those in Study $1 b$. Each question displayed an image of a group of 6 or 12 stick figures and asked which group was best characterized by an attribute (e.g., Which group is impoverished?). Each queried attribute was also a stimulus on the IAT. Questions were presented in a randomly predetermined order.

Participants' answers to the ten questions were transformed to a single variable to allow for direct comparison with IAT D scores. For each question, participants were given a score of zero if they responded that the group of 6 was characterized by the attribute or a score of one if they responded that the group of 12 was characterized by the attribute. Scores for the positive attribute (e.g., rich) and its synonyms (e.g., wealthy) were summed, as were the scores for the negative attribute (e.g., poor) and its synonyms (e.g., impoverished). The sum for the negative attribute and its synonyms was then subtracted from the sum for the positive attribute and its synonyms. This process yielded a value from -5 to 5 . Negative values indicate an explicit rating that the smaller group is the positive attribute, whereas positive values indicate an explicit rating that the larger group is the positive attribute. 
Figure 4. Mean explicit ratings and implicit associations for each attribute in Study 3. Error bars are $95 \% \mathrm{Cls}$.
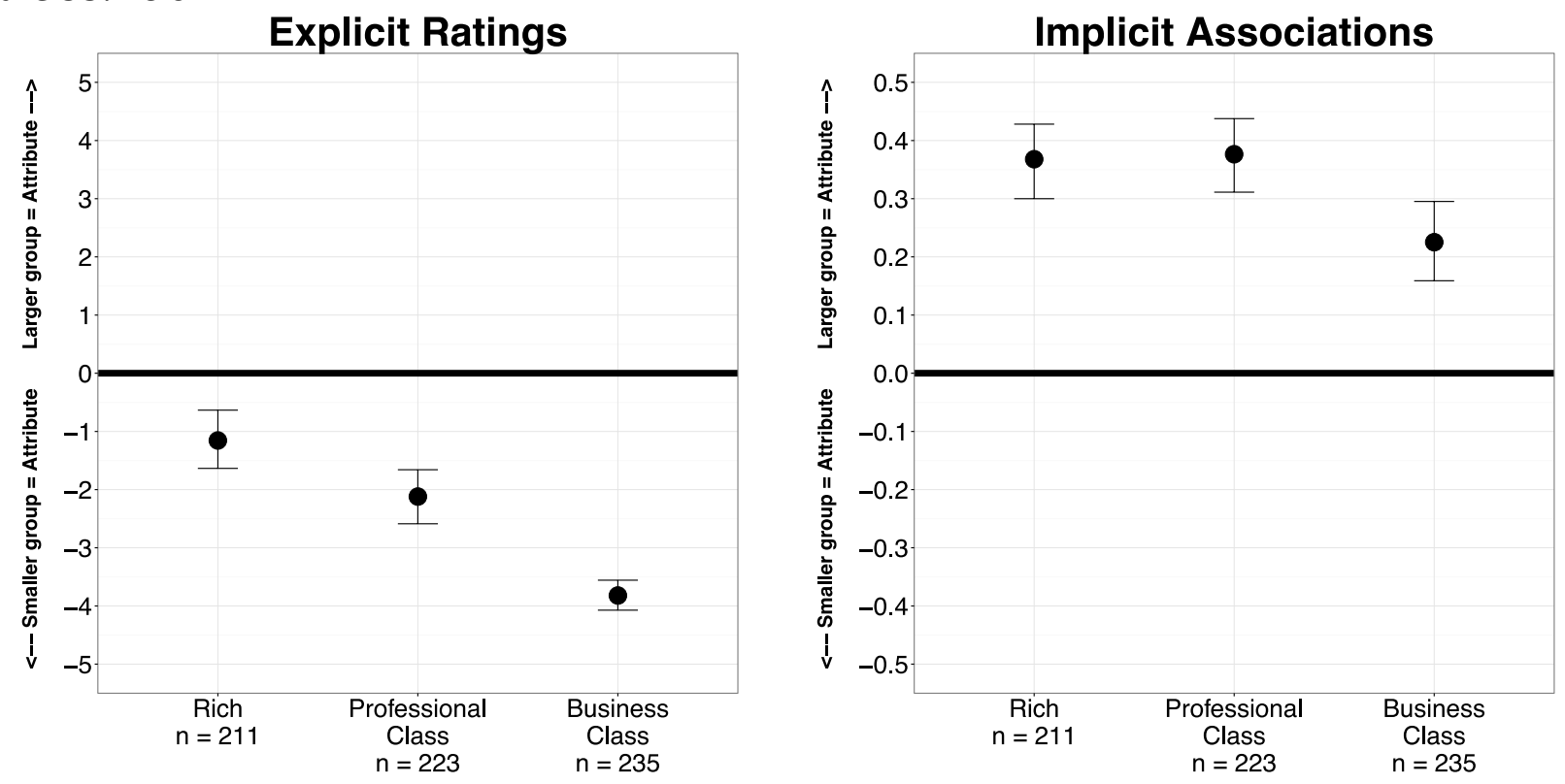

Results and Discussion. Figure 4 clearly illustrates the explicit-implicit dissociation in a withinsubjects design. Smaller groups were explicitly rated as rich, professional class, and business class (Ms $<-1.15$, Wilcoxon signed rank test $V s<6603, p s<.0001) .{ }^{7}$ However, larger groups were implicitly associated with these same attributes $(M s>0.22$, one-sample $t s>6.38$, $p s<$ .0001 , Cohen's $d s>0.41)$. Considering how strong the explicit intuition is that smaller groups are higher in status/competence than larger groups - especially with respect to the specific attributes tested - the degree of dissociation is striking. There is little hesitancy in reporting that smaller groups are rich, professional class, and business class compared to larger groups. And yet implicitly, larger groups instead of smaller groups are robustly associated with these attributes.

\footnotetext{
${ }^{7}$ Because explicit ratings were not normally distributed (see Figure S3), this nonparametric version of a onesample $t$ test was appropriate. But regardless of whether parametric or nonparametric analyses are conducted, the substantive conclusion remains the same. We also calculated a Cohen's kappa for each participant comparing his or her responses to a hypothetical set of responses in which the larger group was always rated as low in status/competence and the smaller group was always rated as high in status/competence. The average Cohen's kappa in the rich, professional class, and business class conditions were $0.23,0.42$, and 0.76 , respectively, all of which indicate fair to substantial agreement.
} 


\section{Study 4}

Thus far, smaller groups have been explicitly rated as higher in status/competence than larger groups. But this is not always the case. Consider Australia and New Zealand, two countries that are widely known to differ in size but not in status/competence. Australia and New Zealand are extremely similar in culture, health outcomes, and educational attainment. Both countries were British colonies. Life expectancies are virtually identical: 81.4 years in New Zealand and 82.3 in Australia (World Bank, 2016). And literacy rates in both countries exceed 96\% (UNESCO, 2013).

Given these similarities, we expect that on explicit ratings, participants will indicate that Australia and New Zealand are equally classy, healthy, and smart - three attributes from the status/competence dimension. However, if it is indeed the case that larger groups accrue greater status/competence on the IAT, then Australia should be implicitly associated with classy, healthy, and smart. If this result is observed, then it would demonstrate how pervasively dissociated group perception can be.

Participants. Participants were volunteer visitors to Project Implicit. Only U.S. citizens were recruited for this study so that direct experience with Australia or New Zealand would be minimized. Of the 179 participants who completed the IAT, 1 was excluded for going faster than $300 \mathrm{~ms}$ on $10 \%$ or more of trials, in accordance with the Greenwald, Nosek, \& Banaji (2003) and well within expected rates. An additional 7 participants were excluded for not completing all explicit measures. The final sample consisted of 171 participants ( $M_{\text {age }}=40.35$ years, $S D=$ 15.65; 106 females, 65 males).

Methods. First, participants were shown a map of Australia and New Zealand as a visual reminder of the size difference between the two countries. Next, participants completed an IAT in which the concepts were Australia and New Zealand and the attributes were Classy vs. Crude, Healthy vs. Sick, or Smart vs. Stupid. One of these three attribute pairs was randomly assigned to each participant in a between-subjects design. All IAT stimuli are available in the appendix. The order of the critical blocks was counterbalanced. $D$ scores were calculated such 
that negative values indicate an implicit association between New Zealand and the positive attribute (i.e., classy, healthy, and smart) and positive values indicate an implicit association between Australia and the positive attribute.

After completing the IAT, participants answered one explicit question about how classy, healthy, or smart the people of Australia vs. New Zealand are. The content of the explicit question matched the attribute participants were randomly assigned in the IAT. Explicit answers were provided on a Likert-type scale ranging from -3 to 3 , where negative values indicate that New Zealand is classier, healthier, or smarter and where positive values indicate that Australia is classier, healthier or smarter. These questions are available in the appendix.

Figure 5. Mean explicit ratings and implicit associations for each attribute in Study 4. Error bars are $95 \% \mathrm{Cls}$.

Explicit Ratings

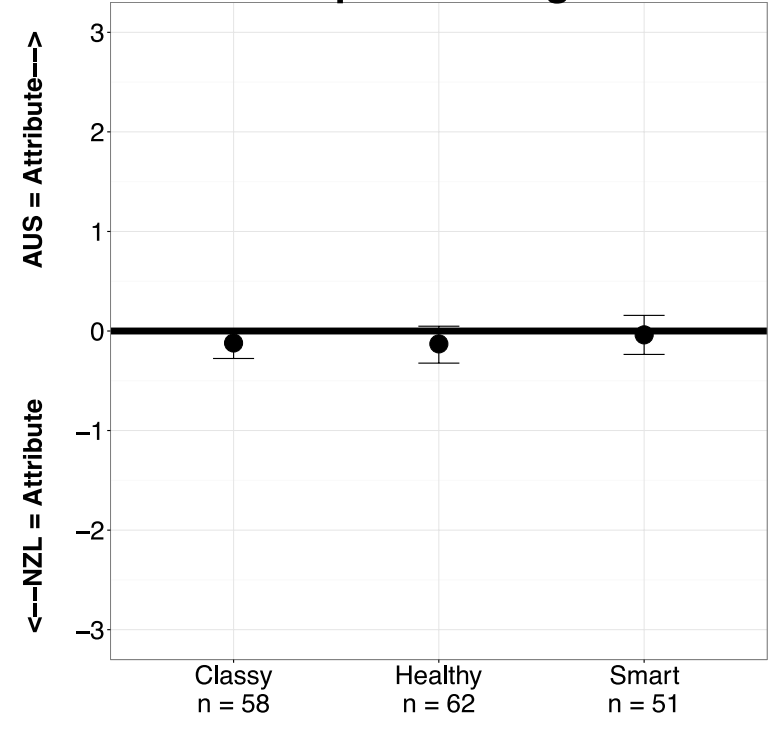

Implicit Associations

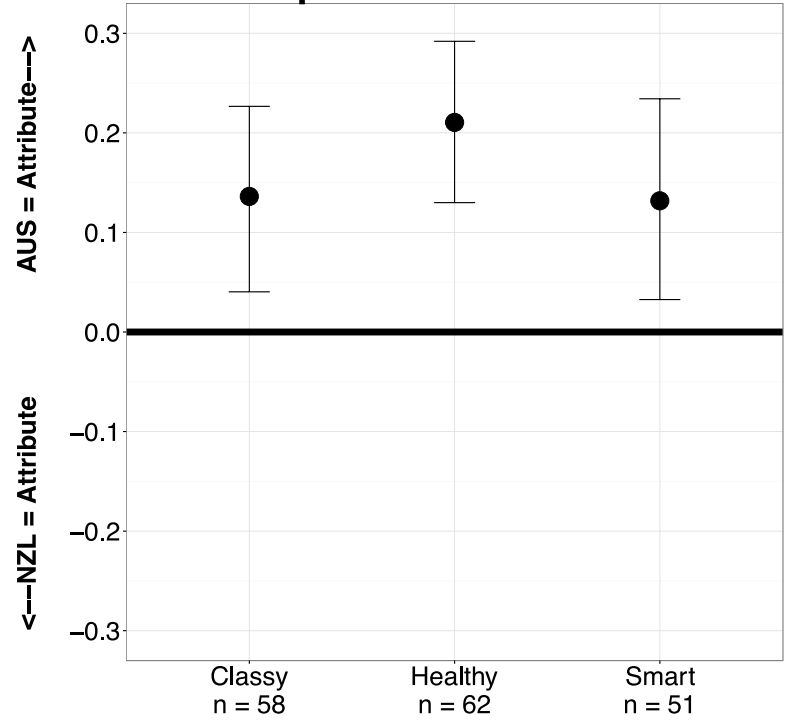

Results and Discussion. Figure 5 clearly shows the predicted explicit-implicit dissociation. As expected, neither group was explicitly rated as classier, healthier, or smarter than the other. Both Australia and New Zealand were rated as equally classy $(M=-0.12, S D=0.59, t(57)=-1.55$, $p=.13)$, equally healthy $(M=-0.13, S D=0.71, t(61)=-1.43, p=.16)$ and equally smart $(M=-$ 
$0.04, S D=0.69, t(50)=-0.40, p=.69)$. These null effects show that participants did not explicitly differentiate between these two groups.

By contrast, on the IAT, participants did differentiate between these two groups in a manner consistent with previous findings. The larger group of Australia was implicitly associated with classy $(M=0.14, S D=0.38, t(57)=2.76, p=.008$, Cohen's $d=0.36)$, healthy $(M$ $=0.21, S D=0.33, t(61)=5.09, p<.0001$, Cohen's $d=0.65)$, and smart $(M=0.13, S D=0.38$, $t(50)=2.51, p=.015$, Cohen's $d=0.35)$.

These findings show that the explicit-implicit dissociation in status/competence can arise even when two groups are explicitly rated to be the same, as it is not always the case that smaller groups are more elite. Explicit cognition recognizes that Australia and New Zealand are extremely similar in terms of culture, health outcomes, and educational attainment. But implicitly, the larger group of Australia is implicitly associated with classy, healthy, and smart.

\section{Discussion}

Group size plays a complex role in eliciting social inferences. While smaller and larger groups were rated as equally warm/good, smaller groups were rated as higher in status/competence than larger groups because socioeconomic elites are few in number. A quite different picture emerged when the measure was implicit. Smaller and larger groups were equally associated with warmth/goodness, mirroring explicit ratings. However, in direct contrast with explicit ratings, larger instead of smaller groups were implicitly associated with high status/competence. Even when two groups are known to be equal in status/competence, the larger group was still implicitly associated with greater status/competence.

Why is there is an explicit-implicit dissociation? First, we ruled out the possibility that the dissociation is merely an artifact. On the IAT, larger groups may be associated to a greater degree with any attribute. But larger groups were not associated with greater warmth/goodness compared to smaller groups. Alternatively, larger groups might be associated with more positive attributes than smaller groups. But this cannot be the case since both sized groups were equally associated with pleasant. Finally, it is also unlikely that social desirability led participants to conceal any explicit beliefs that larger groups are actually high in 
status/competence. In Study 1b, participants offered explanations for their ratings that were aligned with the reality that smaller groups tend to hold elite status.

With these possibilities ruled out, we are left with the clear result that automatic cognition demonstrates a robust and mostly incorrect association between larger groups and high status/competence. To understand this result and guide future research, we put forward three possibilities.

First, implicit associations between larger groups and high status/competence may represent an unwarranted extension of the association between larger groups and physical dominance. Since we used abstract stimuli to represent the smaller and larger groups, there was no clear basis to infer status/competence. It is for this very reason that we did not initially use real social groups, which can signal status/competence. Although notably, a dissociation still emerged in Study 4 when real groups were used. However, when abstract stimuli were used, there was a clear basis to infer that the larger group is physically stronger than the smaller group (Maynard Smith \& Parker, 1976; McComb et al., 1994), leading to the possibility that implicit associations between larger groups and high status/competence may emerge from an overgeneralization of the association between larger groups and physical dominance.

On the IAT, participants may have fallen prey to a type of halo effect. Perhaps similar to how perceptions of physical beauty can lead to biased perceptions of dependability, loyalty, and other personality characteristics (Thorndike, 1920; Dion, Berscheid, \& Walster, 1972), perceptions of physical strength might lead to biased perceptions of status/competence. It is not necessarily the case that groups with greater physical strength have the most money and status, and participants indicated as much in their explicit ratings.

A second interpretation is that the extension from physical dominance to high status/competence may be sensible instead of unwarranted. To the extent that larger groups were able to use their physical dominance to accrue resources and gain status/competence, these larger groups may have forged a privileged association with high status/competence. Furthermore, the notion of a small group (e.g., the top 1\%) holding a disproportionate amount of resources is a recent phenomenon that would have been highly unlikely in our evolutionary past, as smaller groups would have been unable to consistently overpower larger groups or 
have a way to safely store resources for long periods of time. So while such an extension from physical dominance to high status/competence may have been valid in ancestral environments, it is not in today's environment where people are well of aware of the fact that the socioeconomic elite are generally few in number and high in status/competence compared to larger groups of people of more modest means.

A third possibility to consider is that implicit associations between group size and status/competence may be a function of one's sociocultural experience. Indeed, IAT results have been interpreted as reflecting traces of such experience (Banaji, Nosek, \& Greenwald, 2004). If one's sociocultural experience includes larger groups of rich, smart, and professional class individuals who fly business class, then the implicit associations between larger groups and these attributes may be facilitated, even though explicit ratings by the same person will accord with the reality that smaller groups typically embody these attributes. Conversely, if one's cultural experience includes larger groups of low socioeconomic status individuals, then both explicit ratings and implicit associations may converge. Replicating these studies in special populations where one's sociocultural experience includes smaller vs. larger groups of high status/competence individuals would provide a clearer test of the generality of the results reported here.

These results have implications for consequential behaviors of helping and harming. Given two groups that vary in size and the decision to help one group and harm the other, perceptions of status/competence may come into play. First, consider the identifiable victim effect: single victims (e.g., baby Jessica; Variety, 1989) are more likely to be helped than larger groups of victims. Explanations include single victims evoking 1) more vivid emotion, 2) greater certainty of death in the absence of help, and 3) more positive impact if help is offered (Jenni \& Loewenstein, 1997). Underlying these explanations may be the perception that a single victim is low in status/competence while a larger group is high in status/competence. The implicit association between larger groups and high status/competence may lead larger groups to be viewed as either needing less help or less likely to benefit substantially from help. Thus, identifiable victims, who are smaller in number, may receive a disproportionate share of help. 
Second, consider the trolley problem. Will one person be killed to save five? Or will nothing be done, resulting in the deaths of five people? People who choose the latter generally decide faster than those who choose the former (Baron et al., 2012), a result typically interpreted in a dual systems framework: people quickly heed an affective aversion to intentionally inflicting harm (Greene, 2013). But this quick decision may also stem, in part, from an implicit association between group size and status/competence. If one group must be harmed, then harming a group perceived to be low in status/competence (i.e., the lone individual) might be seen as worse than harming a group perceived to be in high in status/competence (i.e., the larger group of five).

Implicit associations have predicted various behaviors above and beyond explicit ratings (Dovidio et al., 2002; Penner et al., 2010; Spence \& Townsend, 2007). These implicit associations might also predict helping and harming behaviors towards groups that vary in size. While this possibility awaits future research, the replicated results reported here based on large samples of participants suggest that within the same perceiver, two conflicting mental representations co-exist. Explicit representations of the social hierarchy coincide with reality, for smaller groups that tend to be high in status/competence occupy the apex and larger groups that tend to be low in status/competence are below. Implicit mental representations appear to invert this. When more automatic cognition is engaged, larger groups are viewed as holding the most status/competence, contradicting both objective reality as well as consciously reported explicit beliefs.

\section{Acknowledgements}

This work was supported by a National Science Foundation Graduate Research Fellowship (DGE 1144152) to J.C. 


\section{References}

Allport, G.W. (1954). The nature of prejudice. Cambridge, MA: Perseus Books.

Asch, S.E. (1951). Effects of group pressure upon the modification and distortion of judgments. In H. Guetzkow (Ed.), Groups, leadership and men (pp. 177-190). Pittsburg, P.A.: Carnegie Press.

Banaji, M.R., Nosek, B.A., \& Greenwald, A.G. (2004). No place for nostalgia in science: A response to Arkes and Tetlock. Psychological Inquiry, 15(4), 279-310.

Baron, J., Gurcay, B., Moore, A.B., \& Starcke, K. (2012). Use of a Rasch model to predict response times to utilitarian moral dilemmas. Synthese, 189(1), 107-117.

Campbell, D.T. (1958). Common fate, similarity, and other indices of the status of aggregates of persons as social entities. Behavioral Sciences, 3(1), 14-25.

Craig, M.A., \& Richeson, J.A. (2014). On the precipice of a "majority-minority" America: Perceived status threat from the racial demographic shift affects White Americans' political ideology. Psychological Science, 25(6), 1189-1197.

Dasgupta, N., Banaji, M.R., \& Abelson, R.P. (1999). Group entitativity and group perception: Associations between physical features and psychological judgment. Journal of Personality and Social Psychology, 77(5), 991-1033.

Dion, K., Bercheid, E., \& Walster, E. (1972). What is beautiful is good. Journal of Personality and Social Psychology, 24(3), 285-290.

Dovidio, J.F., Gaertner, S.L., \& Kawakami, K. (2002). Implicit and explicit prejudice and interracial interaction. Journal of Personality and Social Psychology, 82(1), 62-68.

Fiske, S.T., Cuddy, A.J.C., Glick, P., \& Xu, J. (2002). A mode of (often mixed) stereotype content: Competence and warmth respectively follow from perceived status and competition. Journal of Personality and Social Psychology, 82(6), 878-902.

Fiske, S.T., Cuddy, A.J.C., \& Glick, P. (2006). Universal dimensions of social cognition: Warmth and competence. Trends in Cognitive Sciences, 11(2), 77-83.

Greene, J.D. (2013). Moral tribes: Emotion, reason, and the gap between us and them. New York: Penguin Books.

Greenwald, A.G., McGhee, D.E., \& Swartz, J.L.K. (1998). Measuring individual differences in implicit cognition: The Implicit Association Test. Journal of Personality and Social Psychology, 74(6), 1464-1480. 
Greenwald, A.G., Nosek, B.A., \& Banaji, M.R. (2003). Understanding and using the Implicit Association Test: I. An improved scoring algorithm. Journal of Personality and Social Psychology, 85(2), 197-216.

Hamilton, D.L., Sherman, S.J., \& Castelli, L. (2002). A group by any other name: The role of entitativity in group perception. European Review of Social Psychology, 12(1), 139-166.

Hewstone, M., Rubin, M., \& Willis, H. (2002). Intergroup bias. Annual Review of Psychology, 53, 575-604.

Jenni, K.E., \& Loewenstein, G. (1997). Explaining the "identifiable victim effect." Journal of Risk and Uncertainty, 14, 235-257.

Kerr, N.L. (1989). Illusions of efficacy: The effects of group size on perceived efficacy in social dilemmas. Journal of Experimental Social Psychology, 25(4), 287-313.

Latane, B. (1981). The psychology of social impact. American Psychologist, 36(4), 343-356.

Levine, J.M., \& Moreland R.L. (1990). Progress in small group research. Annual Review of Psychology, 41, 585-634.

Lewin, K. (1947). Concept, method and reality in social science: Social equilibria and social change. Human Relations, 1(1), 5-41.

Lickel, B., Hamilton, D. L., Wieczorkowska, G., Lewis, A., Sherman, S. J., \& Uhles, A.N. (2000). Varieties of groups and the perception of group entitativity. Journal of Personality and Social Psychology, 78, 223-246.

Macrae, C.N., \& Bodenhausen, G.V. (2000). Social cognition: Thinking categorically about others. Annual Review of Psychology, 51(1), 93-120.

Magee, J.C., \& Galinsky, A.D. (2008). Social hierarchy: The self-reinforcing nature of power and status. The Academy of Management Annals, 2(1), 351-398.

Markham, S.E., Dansereau, F., \& Alutto, J.A. (1982). Group size and absenteeism rates: A longitudinal analysis. The Academy of Management Journal, 25(4), 921-927.

Maynard Smith, J. \& Parker, G.A. (1976). The logic of asymmetric contests. Animal Behaviour, 24(1), 159-175.

McComb, K., Packer, C., \& Pusey, A. (1994). Roaring and numerical assessment in contests between groups of female lions, Panthera leo. Animal Behaviour, 47(2), 379-387. 
Moynihan, C. (2015, April 2). Occupy Wall Street, the Tour. The New York Times. Retrieved from http://www.nytimes.com

Norton, M.I., \& Ariely, D. (2011). Building a better America - One wealth quintile at a time. Perspectives on Psychological Science, 6(1), 9-12.

Nosek, B.A., Smyth, F.L., Hansen, J.J., Devos, T., Lindner, N.M., Ranganath, K.A., Smith, C.T., Olson, K.R., Chugh, D., Greenwald, A.G., \& Banaji, M.R. (2007). Pervasiveness and correlates of implicit attitudes and stereotypes. European Review of Social Psychology, 18(1), 1-53.

Nosek, B.A. (2005). Moderators of the relationship between implicit and explicit evaluation. Journal of Experimental Psychology: General, 134(4), 565-584.

Penner, L.A., Dovidio, J.F., West, T.V., Gaertner, S.L., Albrecht, T.L., Dailey, R.K., \& Markova. T. (2009). Aversive racism and medical interactions with black patients: A field study. Journal of Experimental Social Psychology, 46(2), 436-440.

Pietraszewski, D., \& Shaw, A. (2015). Not by strength alone: Children's conflict expectations follow the logic of the asymmetric war of attrition. Human Nature, 26, 44-72.

Pinto, L.J., \& Crow, K.E., (1982). The effect of size on other structural attributes of congregations within the same denomination. Journal for the Scientific Study of Religion, 21, 304-316.

Pun, A., Birch, S., \& Baron, A.S. (2016). Infants use relative numerical group size to infer social dominance. Proceedings of the National Academy of Sciences of the United States of America, 113(9), 2376-2381.

Reeder, G.D., Kumar, S., Hesson-McInnis, M.S., \& Trafimow, D. (2002) Inferences about the morality of an aggressor: The role of perceived motive. Journal of Personality and Social Psychology, 83(4), 789-803

Rydell, R.J., McConnell, A.R., Strain, L.M., Claypool, H.M., \& Hugenberg, K. (2007). Implicit and explicit attitudes respond differently to increasing amounts of counterattitudinal information. European Journal of Social Psychology, 37(5), 867-878.

Spence, A., \& Townsend, E. (2007). Predicting behavior towards genetically modified food using implicit and explicit attitudes. British Journal of Social Psychology, 46, 437-457.

Tajfel, H., \& Turner, J.C. (1986). The social identity theory of intergroup behavior. In S. Worschel \& W.G. Austin, eds. The Social Psychology of Intergroup Relations. Monterey, CA: Brooks/Cole. pp. 33-37. 
Thorndike, E.L. (1920). A constant error in psychological ratings. Journal of Applied Psychology, 4(1), 25-29.

UNESCO (2016). Effective Literacy Practice, Asia and the Pacific. Available at http://www.unesco.org/uil/litbase/?menu=14. Accessed August 12, 2016.

Variety (1989). TV Reviews-Network. Everybody's Baby. Volume 335:7, May 31.

Wilson, M.L., \& Wrangham, R.W. (2003). Intergroup relations in chimpanzees. Annual Review of Anthropology, 32, 363-392.

Worchel, S., Axsom, D., Ferris, F., Samaha, G., \& Schweizer, S. (1978). Determinants of the effect of intergroup cooperation on intergroup attraction. Journal of Conflict Resolution, 22(3), 429439.

World Bank (2016). Life expectancy at birth, total (years). Available at http://data.worldbank.org/indicator/SP.DYN.LE00.IN. Accessed August 122016. 


\section{Appendix}

Example images of smaller and larger groups used Studies 1-3

$\dot{*} \stackrel{*}{*} \frac{*}{*} \dot{*}$

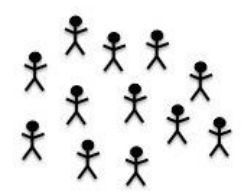

Study 1a: Attribute Pairs and Supplemental Data

\begin{tabular}{|c|c|c|}
\hline Physical Dominance & Warmth/Goodness & Status/Competence \\
\hline Strong-Shaky & Generous-Stingy & Healthy-Sick \\
Powerful-Helpless & Warm-Cold & Smart-Stupid \\
& Nice-Mean & Classy-Crude \\
& Honest-Dishonest & White Collar-Blue Collar \\
& Pleasant-Unpleasant & Rich-Poor \\
& & Business Class-Economy Class \\
\hline
\end{tabular}

\begin{tabular}{|c|c|}
\hline Practice & Emotion \\
\hline Simple-Complex & Envied-Disgusting \\
Light-Heavy & Admired-Pitied \\
Slow-Fast & Envied-Admired \\
& Pitied-Disgusting \\
\hline
\end{tabular}

